\title{
GESTÃO DE INDICADORES DE DESEMPENHO EM TEMPO REAL APLICADOS A LAMINAÇÃO, ZINCAGEM E FOLHAS METÁLICAS*
}

\author{
Alexsandro Marcio da Silva ${ }^{1}$ \\ Bruno Tonioni Cunha ${ }^{2}$ \\ Chrysler F. Peres Guimarães ${ }^{3}$ \\ Eri Elias de Souza Junior ${ }^{4}$ \\ Felipe Martins da Silva ${ }^{5}$ \\ Lucio Oliveira Magalhães ${ }^{6}$
}

Resumo

Com o objetivo de prover informações precisas, coesas e em tempo real aos gestores da Diretoria da Usina Presidente Vargas (UPV) para a tomada de decisões, foi criado o projeto para Gestão de Indicadores de Desempenho em Tempo Real com o foco no processo produtivo e performance das áreas de Laminação (a quente e a frio), Zincagem e Folhas Metálicas. O projeto foi desenvolvido em fases, onde cada fase contemplava um determinado número de equipamentos, áreas e plantas, com visualização em drill down. Utilizando os conceitos de Data Visualization e Operational Intelligence, foi possível integrar e centralizar as informações de diversas fontes de dados, tais como, PIMS, MES, LIMS, ERP, Supervisórios, PROCOM's e entradas manuais. Padronizar as informações de controle do processo produtivo entre os gestores facilita a identificação de problemas e suas causas, e permite analisar simultaneamente várias áreas e plantas. Exibir em tempo real perdas operacionais em decorrência de desvios de processo, torna o processo de tomada de decisão mais rápido e assertivo, contribuindo para a melhoria da performance dos equipamentos, redução de riscos de falhas, e além disso aumenta a vida útil dos equipamentos e otimiza a monitoração dos processos.

Palavras-chave: Indicadores em tempo real; Visualização de dados; Inteligência operacional; TI Industrial.

\section{REAL TIME KPY MANAGEMENT APPLIED TO ROLLING, GALVANIZING AND TIN PLATE}

\section{Abstract}

In order to provide precise and cohesive information in real time to the management of the Usina Presidente Vargas (UPV), the Real Time KPI Management Project was designed. The project was focused on three main areas: Rolling, Galvanizing and Tin Plate. The project was developed in phases, where each phase involved a specific set of equipments, areas and plants, with drill down visualization. Using the Data Visualization and Operational Intelligence concepts, allowed to integrate and centralize information from different sources, e.g. PIMS, MES, LIMS, ERP, Supervisory, PROCOM's and manual entries. The standardization of process information between managers helps them to identify problems and their causes and analyze various plants and areas simultaneously. The real-time monitoring of the operational losses improves the making decision process becoming it faster and more assertive, contributing to the enhancement of the equipment performance, higher lifetime and the risk reduction.

Keywords: Real-time KPI; Data visualization; Operational intelligence; Industrial IT.

Gerente de projetos, TI Industrial, Chemtech a Siemens Business, Brasil.

Líder de projetos, TI Industrial, Chemtech a Siemens Business, Brasil.

Técnico Especialista, Propriedade Intelectual, Companhia Siderúrgica Nacional, Brasil.

Engenheiro de Sistemas, TI Industrial, Chemtech a Siemens Business, Brasil.

Engenheiro de Sistemas Senior, TI Industrial, Chemtech a Siemens Business, Brasil.

Especialista em Soluções Industriais, GTA, Companhia Siderúrgica Nacional, Brasil.

* Contribuição técnica ao $18^{\circ}$ Seminário de Automação e TI Industrial, 23 a 26 de setembro de 2014, São Paulo, SP, Brasil. 


\section{INTRODUÇÃO}

Buscando aumentar a eficiência de suas operações, as empresas cada vez mais vêm utilizando softwares e sistemas computacionais que automatizam e auxiliam os operadores e coordenadores nas operações do dia-a-dia da planta. Muito desses sistemas possuem a capacidade de coletar e armazenar uma grande quantidade de informações de processo e de produção, que são extremamente valiosas para que gestores e coordenadores tomem decisões de forma mais preventiva e mais assertiva.

Um sistema de Data Visualization (DV) tem como principal objetivo disponibilizar informações, desde dados reais de produção até dados consolidados de eficiência e indicadores de desempenho, para diversos níveis hierárquicos de uma empresa, em um formato padronizado, organizado e de fácil acesso.

Com o objetivo de disponibilizar os principais indicadores de desempenho para todos os gestores da Diretoria da Usina Presidente Vargas (UPV) em tempo real, buscando a integração dos processos e recursos, e contribuindo para a melhoria de performance dos equipamentos e do processo produtivo, a CSN iniciou em 2008 o projeto de Gestão de Indicadores de Desempenho em Tempo Real chamado RtPM (Real-time Performance Management) que foi executado em cinco fases, abrangendo na sua última fase as áreas de Laminação à Quente, Laminação à frio, Zincagem e Folhas Metálicas.

\section{MATERIAIS E MÉTODOS}

A implementação de um projeto de Data Visualization não visa desativar ou substituir outros sistemas ou ferramentas, e sim centralizar as informações dos sistemas existentes em uma única plataforma, de forma a padronizar tanto a visualização de indicadores quanto a forma o como eles devem ser calculados.

O foco do RtPM da CSN são os indicadores de processo e de desempenho da produção que podem ser divididos em dois grupos:

- Indicadores de Processo: são indicadores provenientes diretamente do processo, e geralmente são exibidos de forma "bruta" (i.e. não necessitam de cálculos), pois representam o estado do processo naquele momento. Exemplo: temperatura do forno, pressão de um duto, vazão de um tanque, corrente do motor, etc.

- Indicadores de Produção: são indicadores que geralmente representam uma consolidação de valores da produção, e necessitam de cálculos muitas vezes complexos. Exemplo: tempo de parada, produção diária (em toneladas), produtividade, eficiência, rendimento metálico, etc.

Com base nessa classificação foi feito um levantamento dos indicadores que a CSN já acompanhava e como eles eram obtidos e calculados. Para tornar os indicadores online foi necessário fazer uma análise detalhada da automação, e verificar se todos os dados necessários estavam disponíveis para a integração com o RtPM. Em muitos casos foram necessários investimentos em automação para disponibilizar as informações necessárias.

Com os indicadores definidos, o próximo passo foi a definição das telas, sinóticos e a melhor forma de apresentar os indicadores no RtPM. O conceito de drill down se resume em apresentar a informação do mais generalista ao mais detalhista, ou seja, começando pelo nível da diretoria, visão gerencial, equipamentos e detalhes do processo. Dessa forma a navegação no sistema fica intuitiva para os usuários e ao

* Contribuição técnica ao $18^{\circ}$ Seminário de Automação e TI Industrial, 23 a 26 de setembro de 2014, São Paulo, SP, Brasil. 
mesmo tempo permite a padronização de telas e indicadores entre os mesmo níveis, independentemente do tipo do equipamento.

A Figura 1 mostra o menu do RtPM onde é possível obervar o drill down, no caso, do equipamento de Tiras a Frio 3:

- Camada Diretoria: Link "UPV"

- Camada Gerência Geral: "Lam. Frio/Galvanizados"

- Camada Gerência: "Laminação a Frio"

- Camada Staff / Equipamento: "LTF 3"

\begin{tabular}{|c|}
\hline$\triangle$ UPV \\
\hline Entrega \\
\hline$\triangle$ Embarque/Faturamento \\
\hline Metalurgia da Redução \\
\hline Metalurgia do Aço \\
\hline$\checkmark$ Laminaçäo a Quente \\
\hline Lam.Frio/Galvanizados \\
\hline$\searrow$ Laminação a Frio \\
\hline$\leq$ LTF 3 \\
\hline$\unlhd$ Zincagem \\
\hline$\triangle \operatorname{LZC} 1,2,3$ \\
\hline$\unlhd$ Recozimento Contínuo \\
\hline \pm LRCC 1 \\
\hline$\unlhd$ Forno de Caixa \\
\hline$\triangle \mathrm{FRCX} 4$ \\
\hline Linha Acab. Chapas \\
\hline$\triangle$ LACF 4 \\
\hline$\checkmark$ Lamin. Enc. Rev. \\
\hline$y$ LER \\
\hline$y$ Lam. Encruamento \\
\hline$\triangle \mathrm{LE} 1$ \\
\hline Emb. LZ-LFX \\
\hline Folhas Metálicas \\
\hline
\end{tabular}
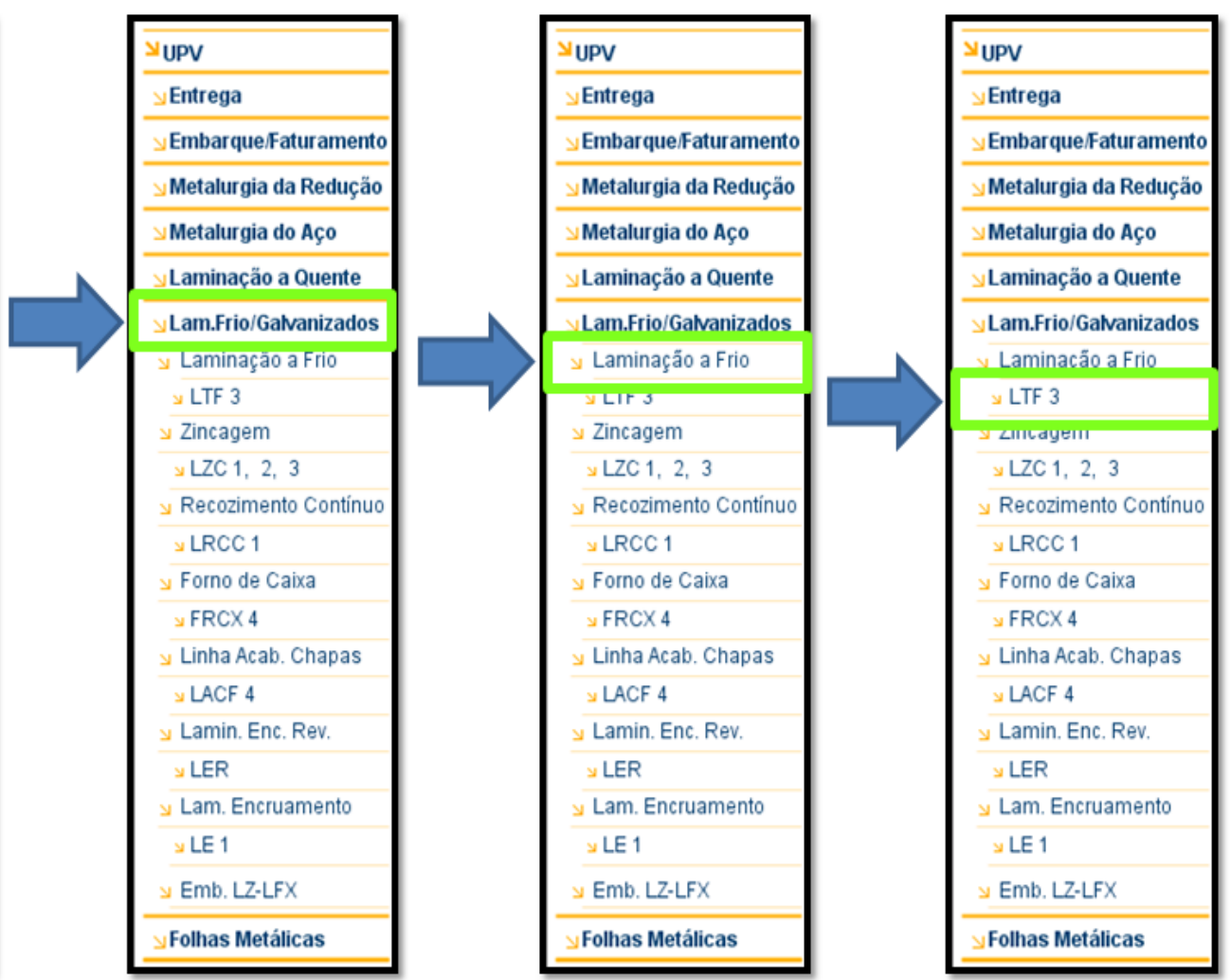

Figura 1: Exemplo drill down do RtPM

Com os indicadores e telas definidos, junto com a estrutura de navegação, a última etapa passa a ser a distribuição dos indicadores em cada tela e nível com a definição da forma de apresentação de cada indicador (trend, chart, barra, label, etc.).

A próxima imagem mostra uma sequência de telas do sistema RtPM. 

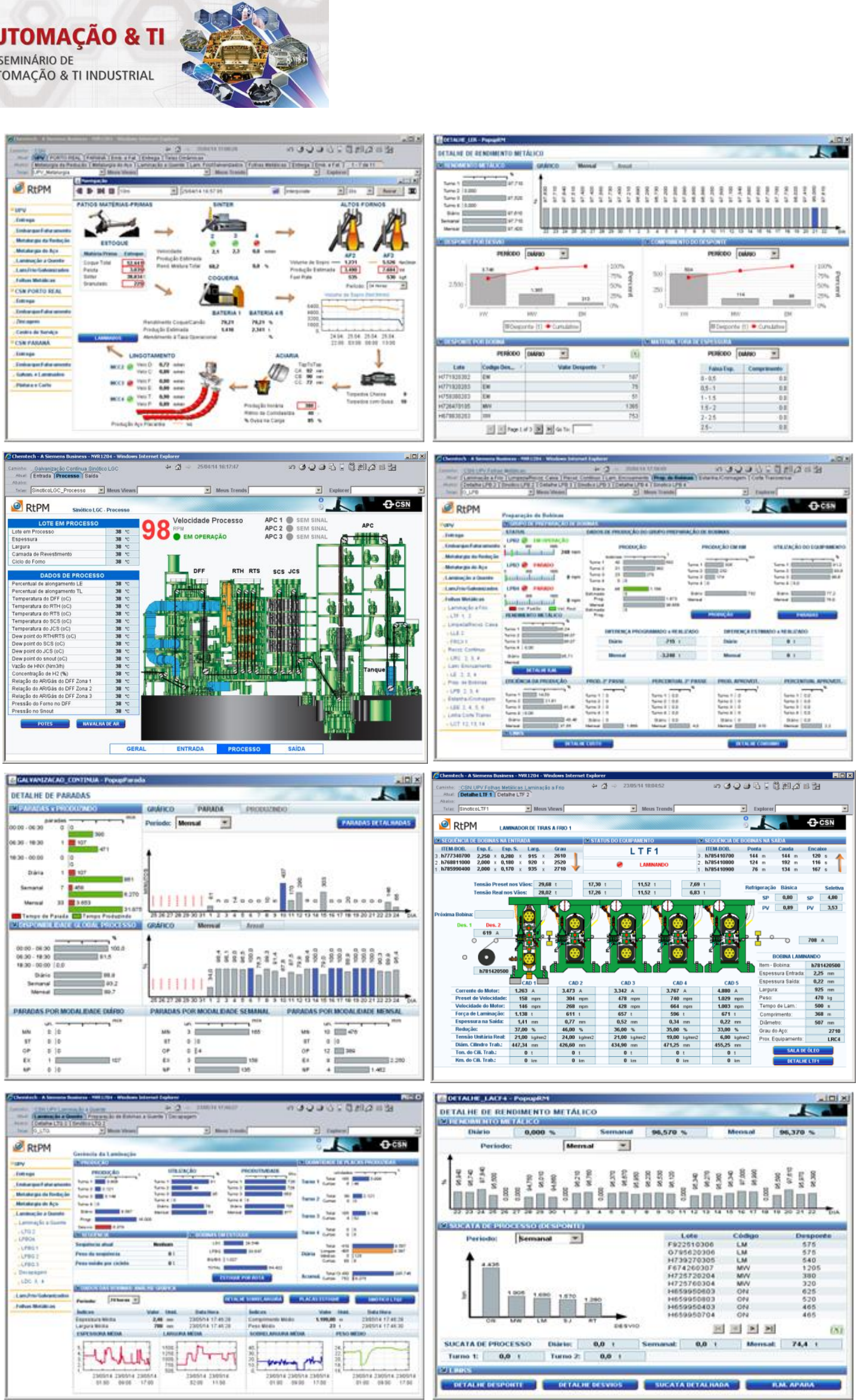

Figura 2: Telas do RtPM

\subsection{Arquitetura}

Um dos grandes desafios da implementação de um sistema de Data Visualization é a necessidade de se obter informações de sistemas distintos (i.e, fornecedores e 
tecnologias diversas) de maneira rápida (on-line) sem que isso impacte na performance dos sistemas.

Uma das características chave dessa ferramenta é a sua capacidade de se conectar com praticamente todos os tipos de sistemas. Um recurso essencial da ferramenta é a existência de uma arquitetura de cache que funciona como um buffer de informações extraídas/coletadas dos diversos sistemas da planta. Uma vez conectada a um sistema, faz a consulta dos dados e armazena essas informações em seu cache. Com isso, todo o acesso à informação para cálculos dos indicadores é otimizada com acesso a este cache evitando a sobrecarga nos sistemas.

A Figura 3 mostra uma arquitetura de cache.

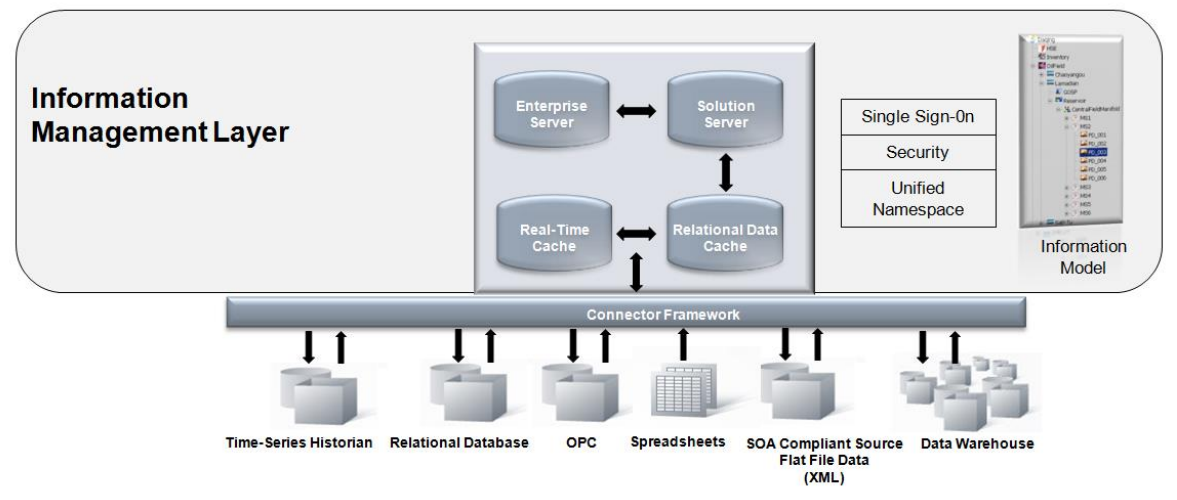

Figura 3: Arquitetura do cache

\section{RESULTADOS E DISCUSSÃO}

A solução RtPM implementada na CSN além de permitir o acompanhamento online dos principais indicadores das áreas implementadas, possui vários recursos gráficos para facilitar a navegação do usuário.

\subsection{Navegação}

A solução RtPM possui menus que permitem uma fácil navegação por todas as telas do sistema ao mesmo tempo que facilita a visualização do conceito de "drill down" da planta:

$>$ Através do menu superior: A Figura 4 mostra o chamado "Menu Superior" na qual qualquer um dos níveis exibidos pode ser clicado diretamente, direcionando a navegação para a tela principal do nível clicado.

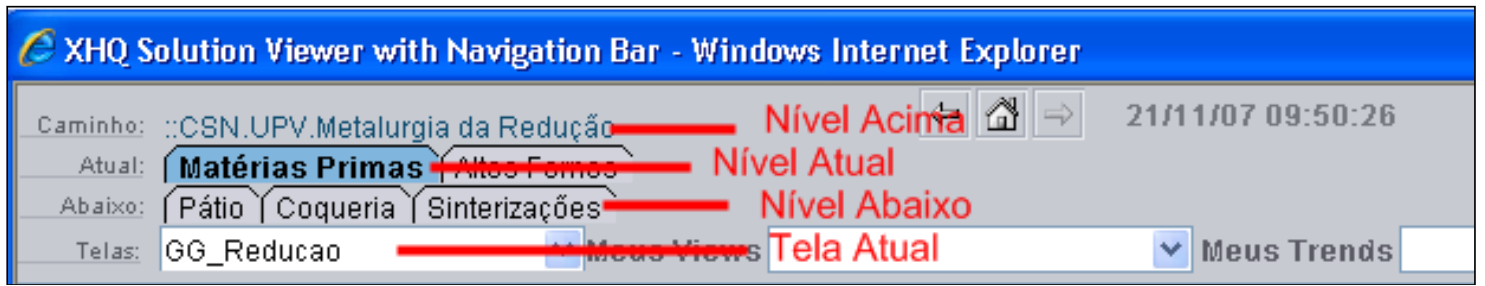

Figura 4: Informações de navegação oferecidas pelo menu superior

Através do menu lateral: o menu lateral é muito semelhante ao menu superior, porém exibe o drill down inteiro da planta de forma mais abrangente alterando-se dinamicamente dependendo do nível organizacional que está sendo visualizado. 


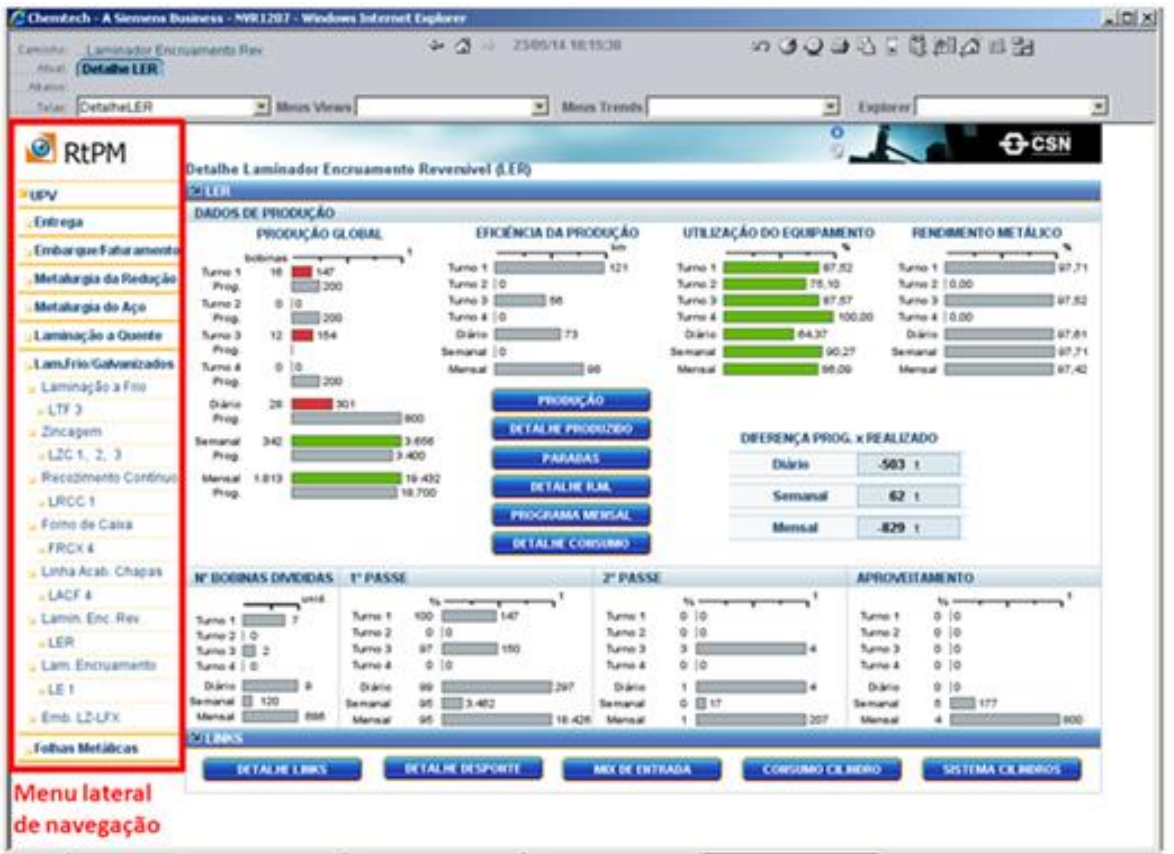

Figura 5: Menu lateral de navegação

Através dos links interativos: Através dos links de cada índice, valor ou figura é possível ser direcionado para as áreas relacionadas aquele índice. Em toda a navegação, sempre que houver um retângulo azul ao redor do ponteiro do mouse, significa que existe o link para alguma tela relacionada.

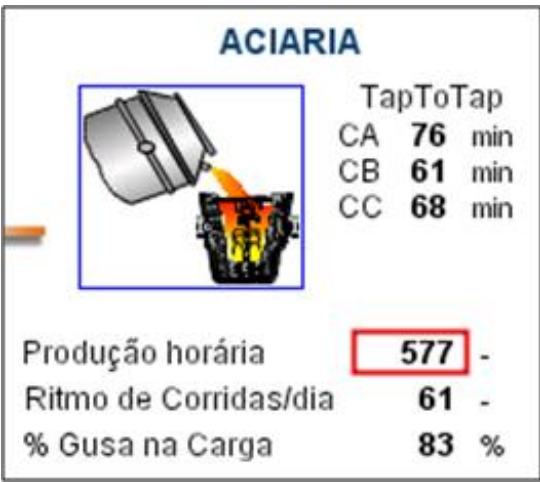

Figura 6: Indicação de existência de link

> Através de visões (ou views) salvas como favoritas: Uma outra forma (e talvez a mais rápida delas) de navegação é através das telas (denominadas views) que foram previamente salvas como sendo favoritas. Cada usuário pode selecionar as telas que mais visita e salvá-las como favoritas. As views favoritas podem ser acessadas diretamente através de uma combo no menu superior, conforme ilustra a figura a seguir:

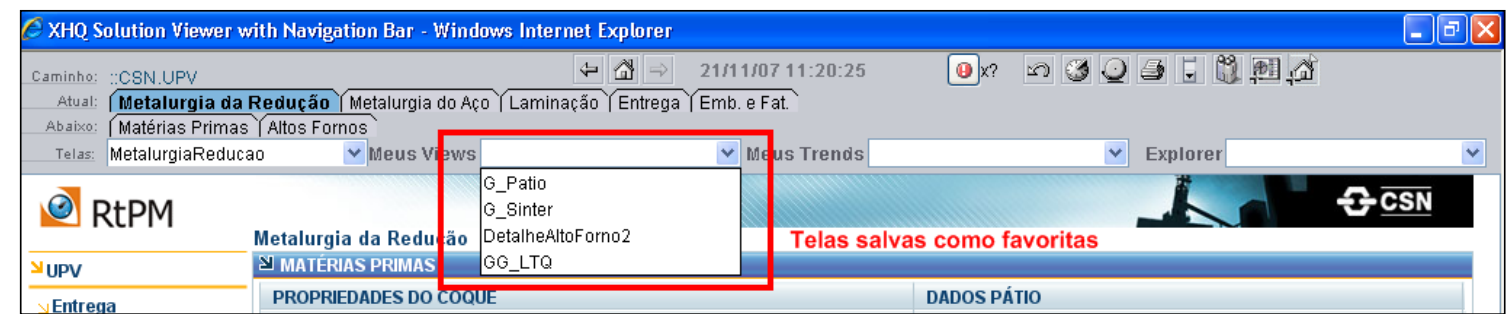

Figura 7: Acessando minhas views favoritas através do menu superior

* Contribuição técnica ao $18^{\circ}$ Seminário de Automação e TI Industrial, 23 a 26 de setembro de 2014, São Paulo, SP, Brasil. 


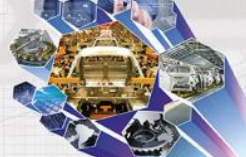

\subsection{Dados em Tempo Real e de Fontes Diversas}

A Figura 8 mostra o fluxo de informação desde os diversos sistemas (PIMS, MES, SAP, etc.) até o RtPM, responsável por centralizar a informação.

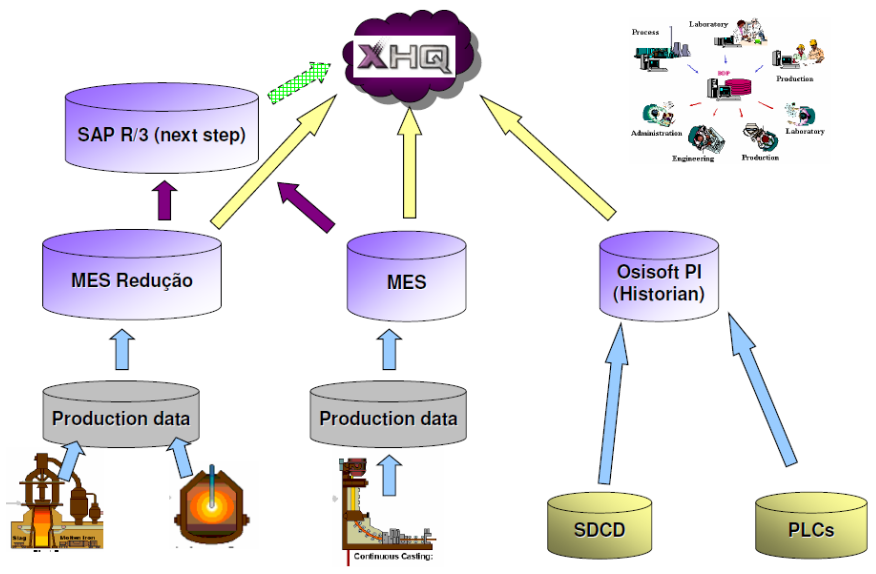

Figura 8: Interconectividade do RtPM

A tecnologia utilizada para a construção do RtPM foi o XHQ da Siemens, conforme ilustrado na figura acima. A ferramenta permite o desenvolvimento fácil e rápido de telas que ajuda na manutenção na solução e na evolução do processo.

A integração com os diversos sistemas permitiu a elaboração de muitos relatórios que precisavam ser confeccionados manualmente, e agora passaram a ser gerados automaticamente, e em tempo real. Além disso, por ter acesso web, qualquer pessoa em qualquer computador dentro da rede CSN, com as devidas autorizações, pode ter acesso ao RtPM.

A figura abaixo mostra uma tela onde é possível acompanhar a produção de cada equipamento em tempo real ao mesmo tempo em que é exibida a quantidade que será entregue no final do dia, baseada no ritmo de produção (também em tempo real). Essa tela permite então que o gestor verifique em segundos se a produção planejada será atendida ou não, e tomar as ações necessárias para o bom andamento do processo. Com essas informações o gestor sai de uma operação REATIVA e passa a ter uma operação PREVENTIVA.

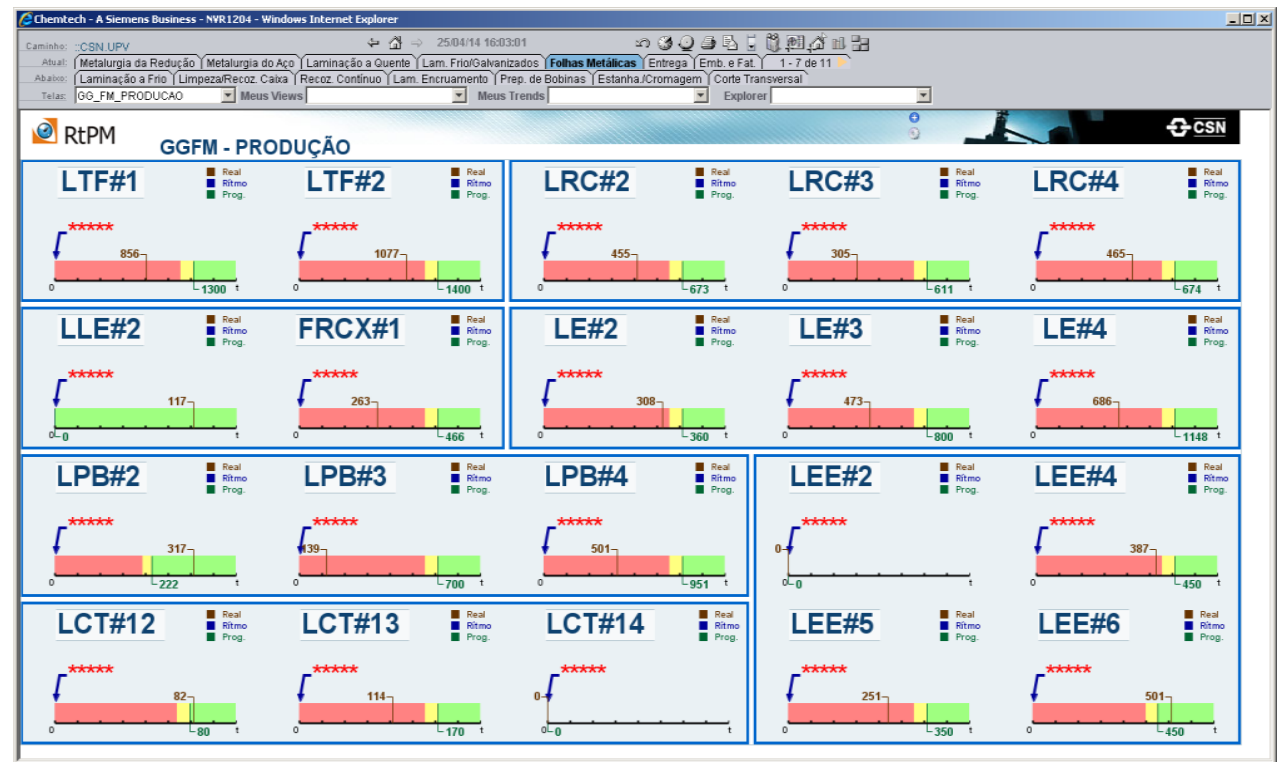

Figura 9: Exemplo de tela que reduziu tempo para tomada de decisão.

* Contribuição técnica ao $18^{\circ}$ Seminário de Automação e TI Industrial, 23 a 26 de setembro de 2014, São Paulo, SP, Brasil. 


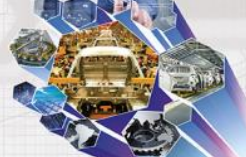

\subsection{Recursos de Personalização}

O RtPM também possui botões que permite ativar ações usadas para personalizar o perfil do usuário, além de oferecer funções extras, como impressão e navegação histórica, conforme descritos abaixo:

Tabela 1: Descrição dos botões da barra de navegação

\begin{tabular}{|c|c|}
\hline cone & Ação \\
\hline ↔ & $\begin{array}{l}\text { Voltar } \\
\text { Ao navegar pelas views no XHQ, um histórico das views que você visitou é armazenado. } \\
\text { Use este botão para voltar a qualquer página que você visitou. }\end{array}$ \\
\hline 메 & $\begin{array}{l}\text { Inicio } \\
\text { Use este botão para voltar ao inicio da solução. }\end{array}$ \\
\hline$\Rightarrow$ & $\begin{array}{l}\text { Avançar } \\
\text { Ao navegar pelas views no XHQ, um histórico das views que você visitou é armazenado. } \\
\text { Use este botão para avançar a qualquer página que você visitou. }\end{array}$ \\
\hline$\Omega$ & $\begin{array}{l}\text { Limpar Filtros } \\
\text { Recarrega a view atual no XHQ (é necessário clicar neste botão para sair do modo } \\
\text { histórico, descrito abaixo) }\end{array}$ \\
\hline 3 & $\begin{array}{l}\text { Histórico } \\
\text { Ativa modo histórico de navegação. Permite navegar através do tempo com todas as } \\
\text { informações provenientes do PI }\end{array}$ \\
\hline 昜 & $\begin{array}{l}\text { Impressão } \\
\text { Usar para imprimir a tela atual. }\end{array}$ \\
\hline E & $\begin{array}{l}\text { Scrollbars (barras de navegação vertical e horizontal) } \\
\text { Exibe ou esconde as scrollbars. }\end{array}$ \\
\hline 99 & $\begin{array}{l}\text { Configurações do Usuário } \\
\text { Permite personalizar o perfil do usuário que está utilizando o XHQ no momento. Configurar } \\
\text { views e trends preferidos para acesso rápido através da combos. }\end{array}$ \\
\hline D目 & $\begin{array}{l}\text { Acrescentar Views as Minhas Views } \\
\text { Acrescentar a view atual na sua lista de Minhas Views. É solicitado que entre com o nome } \\
\text { de uma view, sendo que o nome de padrão exibido na caixa de diálogo é o nome da view } \\
\text { atual exibido no navegador. }\end{array}$ \\
\hline 시 & $\begin{array}{l}\text { Transformar view atual em view padrão } \\
\text { Salva a view atual como sua view-padrão. }\end{array}$ \\
\hline II) & $\begin{array}{l}\text { Estatísticas da view } \\
\text { Estatísticas de uso da View }\end{array}$ \\
\hline
\end{tabular}

\subsection{Principais Ganhos}

> Visibilidade operacional para os Gerentes e Diretores em tempo real: as informações operacionais eram restritas aos sistemas de chão de fábrica vistas somente pelos operadores, e a consolidação das informações era feita somente após o término do dia. Com a integração entre os diversos sistemas, foi possível trazer a visão operacional para todos os níveis da empresa (drill down), e acompanhar de forma online o ritmo da produção para cada equipamento. $\mathrm{O}$ fechamento passou a ser por turno, e cada gerente recebe um email com as informações de produção de sua área;

> Redução do esforço(hh) de elaboração de relatórios gerenciais: o tempo e a dedicação constante de um profissional para a consolidação das informações foi reduzido pelo fato da automatização dos cálculos e relatórios, que passaram a ser acompanhados diretamente no sistema desenvolvido;

> Acompanhamento do consumo de energia: anteriormente, a única forma de consulta às informações de consumo de energia era a verificação direta em instrumentos ou sistemas supervisórios nas áreas de operação, não havendo histórico para comparações ou planejamento de ações de redução de

* Contribuição técnica ao $18^{\circ}$ Seminário de Automação e TI Industrial, 23 a 26 de setembro de 2014, São Paulo, SP, Brasil. 
consumo. Com a entrada do RtPM, foi viabilizado a criação do histórico dessas variáveis possibilitando a análise de consumo e possíveis ações de eficiência energética;

> Visualização online de paradas de equipamento: as paradas dos equipamentos são acompanhadas e analisadas via sistema MES, que possui todas as informações de categorização e causas desses eventos. Contudo, as informações ficam restritas a análises futuras, e não a uma visão online da parada de um recurso. No RtPM foram criadas visões e alarmes que permitem rapidamente identificar um equipamentos parados e visualizar suas causas para tomada de ações eficazes;

> Aumento da utilização das instalações e ativos: o RtPM pode ser utilizado para monitorar e gerar alarmes para variáveis críticas de manutenção de equipamentos e locais de trabalho (vibração de motores, temperaturas, etc.) auxiliando em manutenção preventiva;

$>$ Auxílio em treinamentos de novos membros da equipe: os sinóticos dos equipamentos podem ser utilizados para melhor visualização da sequencia do processo e valores reais de operação da planta. O fluxo de interligação entre as áreas de produção e o conceito de drill down permite uma visão geral de todas as áreas envolvidas no processo. Também disponibilizado pelo sistema o treinamento online da própria ferramenta possibilitando a centralização e rápida atualização do material didático;

$>$ Redução de licenças em sistemas críticos: usuários que precisam de acesso "apenas leitura" passaram a usar apenas o RtPM, liberando/reduzindo o número de licenças necessárias.

> Integração com sistemas interfaceados: O RtPM permite através de seus recursos a visualização de telas/relatórios que fazem parte de sistemas interfaceados não necessariamente conectado ao mesmo repositório de dados. O sistema é capaz de apresentá-las através do endereço web sem a necessidade de novo desenvolvimento.

\section{CONCLUSÃo}

As ferramentas usuais de acompanhamento do processo e produção não possuem o dinamismo necessário para que os gestores façam a tomada de decisão em tempo adequado. As informações precisam ser analisadas de forma conjunta e centralizadas para que se tenha uma visão ampla e total do processo, e assim tomar a decisão mais adequada no momento. O RtPM foi desenvolvido com a finalidade de agregar os conceitos tradicionais de acompanhamento da produção a uma gestão de processo em tempo real, o que possibilita a tomada de ação em todos os níveis de gestão e operação antes que os desvios venham a ocorrer.

\section{REFERÊNCIAS}

1 Manual do usuário - Relatório Técnico da Chemtech (RT-CSN-09396-RTPM-098 Revisão A).

2 Siemens. Solutions for Industrial IT. [acesso em 15 mai. 2014]. Disponível em: http://www.energy.siemens.com/hq/en/industries-utilities/oil-gas/products-systemssolutions/xhq-operations-intelligence.htm.

3 Martins A, Magalhães L, Souza O, Magalhães R. Controle de Processo Automatizado com Auxílio da Matriz T. 68ํㅡㄹ Congresso ABM Internacional, da Associação Brasileira de Metalurgia e Materiais. 2013.

* Contribuição técnica ao $18^{\circ}$ Seminário de Automação e TI Industrial, 23 a 26 de setembro de 2014, São Paulo, SP, Brasil. 